\title{
A Case-Control Study: The Relationship between Alzheimer's disease and Metabolic Syndrome
}

\author{
Figen Varlibas (Corresponding author) \\ Health Sciences University, HSHMYO Mekteb-i Tibbiye-i Sahane Complex, \\ 34668 Uskudar, Istanbul, Turkey \\ E-mail: figenvar@yahoo.com \\ Ozkan Akhan \\ T. C. Haydarpasa Numune Training and Research Hospital \\ 34668 Uskudar, Istanbul, Turkey \\ E-mail: ozkanakhan@hotmail.com
}

\begin{abstract}
Background: Alzheimer's disease (AD) is a neurodegenerative disease advancing gradually with progressive impairment in memory and cognitive functions. It is the most widely recognized reason for dementia and its incidence and prevalence increase with the advancing age. Neurodegenerative processes of the disease can begin in middle ages before clinical manifestations do not manifest themselves, yet. In addition to neuropathological findings specific to $\mathrm{AD}$, the demonstration of atherosclerotic vascular disorders has also been a trigger to investigate cardiovascular risk factors as a risk factor in AD. Objective: In this study, we aimed to investigate the relationship between AD and metabolic syndrome (MetS) which means a bunch of cardiovascular risk factors.

Method: The study is planned as a case-control study. Patients diagnosed with possible-probable AD according to DSM-IV (Diagnostic and Statitical Manual of Mental Disorders), NINCDS-ADRDA (National Institute of Neurologic Communicative Disorders and Stroke-AD and Related Disorders Association) criteria were investigated for the presence of MetS at the time of AD diagnosis. The healthy control group was formed with volunteers having not any neurological disease in their examinations and evaluated as normal cognitively. The diagnosis of MetS was determined according to the demonstrative criteria of "National Cholesterol Education Program Adult Treatment Panel III (NCEP-ATP III)". Findings: Two groups were included in the study: 365 Alzheimer's patients and 158 healthy volunteers. The AD group and the healthy control group were similar in terms of hypertension, hyperlipidemia, diabetes, the low level of high-density lipoprotein cholesterol (HDL-C), a history of ischemic heart disease and a history of cerebrovascular disease. The MetS ratio (38.90\%) in the AD group did not show a significant difference from that (46.83\%) in the healthy control group. The presence of cardiovascular risk factors in Alzheimer's patients at the time of diagnosis of AD was observed to be not as high as in vascular diseases and close to normal values seen in the society.

Comment: In the etiopathogenesis researches of $\mathrm{AD}$, rather than concentrating on causality studies identified with vascular risk factors during the diagnosis period, it might be increasingly practical to focus on the possibility of changing clinical severity and the course.
\end{abstract}

Keywords: Alzheimer's Disease, Metabolic Syndrome

Special Issue of Health Sciences

DOI: $10.7176 / \mathrm{JSTR} / 6-03-42$

Giriş

Alzheimer hastalığı (AH), hafıza ve bilişsel fonksiyonlarda yavaş ilerleyici bir bozulma ile seyreden, günlük yaşam aktivitelerini bozan, nörodejeneratif bir hastalıktır (1). Hafif kognitif yetmezlik (HKY) ise günlük yaşam aktivitelerinin seyrini bozmayan, hafif ama yaşa göre normal olmayıp, yaşa bağlı unutkanlık durumundan daha ileri düzeyde hafıza bozulmasını anlatan klinik bir durumdur. Demans gelişiminde risk faktörü olarak kabul edilir (2).

$\mathrm{AH}$ en sık demans nedeni olup bütün demansların \%50-80'inini oluşturur. İnsidansı ve prevalans1 ilerleyen yaş ile artmaktadır. Genetik ve çevresel etkilerin bir arada etkili olduğu, multifaktöryel bir hastalıktır $(1,3)$. Etyopatogenezinin halen net bilinememesi; hastalığı halen tam düzelten bir tedavinin 
olamamasında etken olduğu gibi, ilerleyişinin durdurulmasına yönelik girişimlerin de başarısını oldukça sınırlandırmıştır. Tanımlandığı 19. yüzyıl ikinci yarısından itibaren, tedavide başarıyı yakalayabilmek adına etyopatogeneze yönelik araştırmalar da devam etmektedir. Hastalığın nörodejeneratif süreçleri, henüz klinik bulgular kendini göstermeden orta yaşlarda başlayabilir $(1,2,3,4)$. Bu nedenle nöropatolojiyi başlatabilecek risk faktörlerinin erken tanımlanması, AH'nın etyopatogenezine 1şık tutabilir. Dahası hastalığın risk faktörleri belirlenebilirse hastalığın önlenmesi ve tedavisi için yeni potansiyel yollar açılabilir.

İlerleyen yaş, aile hikayesi ve apolipoprotein $\mathrm{E}(\mathrm{ApoE}) \in 4$ allelinin varlığı gibi değiştirilemeyen risk faktörleri yanında hastalığın başlamasını, ilerlemesini engelleyebilecek yada geciktirebilecek değiştirilebilen risk faktörleri de önem kazanmıştır $(1,3,5)$.

Klinik olarak demansı olmayan ancak koroner arter hastalığı nedeni ile ölen hastaların beyin kesitlerinin nöropatolojik incelemelerinde, vasküler bozukluklara ilaveten AH'na özgün patolojik bulguların da gösterilmesi sonrasında, hastalığın etyopatogenezinde vasküler risk faktörlerine ilgi artmıştır (6). Hele Alzheimer hastalarının beyinlerinin nöropatolojik incelemelerinde nörofibriler yumaklar, amiloid birikimi, nöronal kayıp gibi AH na özgü nöropatolojik bulguların yanında, artherosklerotik vasküler bozuklukların da gösterilmesi AH'nda vasküler risk faktörlerini daha da çekici hale getirmiştir $(1,3,4,5)$. AH ve kardiyovasküler risk faktörleri arasında nasıl bir ilişki olduğunu araştırmaya yönelik; lipid değerleri, tansiyon, diyabet, obezite...vs ile AH ilişkisini araştıran ve metolojik farklılıkların da etkili olduğu farklı sonuçlar veren çok sayıda çalışma yapılmıştır. Orta yaşta artmış toplam serum kolesterol seviyelerinin geç başlangıçlı AH riskini artırabileceği söyleyen çalışmalar yanında, toplam kolesterol seviyelerinin Alzheimer hastalığı seyrinde azaldığ 1 da belirtilmiştir. Pek çok sayıda çalışmada orta yaştaki yüksek HDL-C (yüksek dansiteli lipoprotein kolesterol) düzeylerinin geç başlangıçlı AH riskini azaltabileceği ifade edilmiş, bu bulgu ile uyumlu olarak yaşlılarda yüksek HDL-C düzeylerinin AH riskini azaltabileceğini düşündüren sonuçların verildiği çalışmalar da yayınlanmıştır. Hipertansiyon için de farklı sonuçlar vardır. Klinik çalışmaların meta analizleri ve pekçok prospektif, gözlemsel çalışmada yüksek tansiyon ve demans arasında tutarlı bir ilişki olduğunu gösterilememiştir. Orta yaş obezitenin demans riskini artığını yönündeki bilgilerde de çelişkiler vardır $(1,3,5,7,8,9)$.

Kardiyovasküler risk faktörleri dendiğinde, genelde aynı kişide birden fazlası birarada bulunmaktadır. Günümüzde çoklu vasküler risk faktörleri "Metabolik Sendrom" (MetS) kavramı ile bir şemsiye altına toplanmaya çalışılmıştır. MetS aslında birkaç kardiyovasküler risk faktörünün bir araya gelerek oluşturduğu bir risk faktörleri demetidir. Daha ayrıntılı tanımlarsak; insülin direnci temelinde, abdominal obezite, arter kan basıncı yüksekliği, aterojenik dislipidemi, glukoz intoleransı veya kan şekeri yüksekliği gibi bilinen kardiyovasküler hastalıklar risk faktörleri topluluğunu tanımlayan bir kavramdır (10)

Biz daha önce yaptığımız bir pilot çalışmada kardiyovasküler risk faktörlerinin AH'ndaki yerini inceleyebilmek amacıyla, AH'nda ve HKY hastalarında MetS varlığını araștırmış ve her ikisi arasında anlamlı bir farklılık bulamamıştık. Çalışmanın devamı şeklinde yürüttüğümüz şimdiki çalışmamızda ise Alzheimer hastalarımızın sayısını artırarak; İstanbul anadolu yakası bölgesinde AH ve benzer yaş sağlıklı gönüllüler grubunda MetS ilişkisini araştırmayı amaçladık.

\section{Metodlar:}

Haydarpaşa Numune Hastanesi, demans polikliniğine unutkanlık şikayeti ile gelen veya getirilen hastalar dan çalışmaya katılmaya onay veren ve/veya aile bireyi tarafından onayı verilen Alzheimer hastaları değerlendirmeye alındı. Unutkanlık şikayeti ile gelen hastalarımıza uyguladığımız rutin sistemik, metabolik biyokimyasal incelemeler ve beyin görüntüleme incelemeleri yapıldı.

DSM-IV (Diagnostic and Statitical Manual of Mental Disorders-IV) ve NINCDS-ADRDA (National Institute of Neurologic Communicative Disorders and Stroke-AD and Related Disorders Association) kriterlerine göre olası-muhtemel Alzheimer hastalığı tanısı alan hastalar, tanı aldığı dönem için MetS varlığı açısından incelendi. İlave olarak zaten özgeçmiş incelenmesinde normalde sorguladığımız hastalıklardan iskemik kalp hastalığı ve beyin damar hastalı̆̆ $\breve{v a r l}_{\breve{g}} \breve{b}_{1}$ bilgileri de çalışmaya dahil edildi. Sağlıklı kontrol grubu; yaygın ağrı yada başağrısı nedeniyle ayaktan poliklinik muayenesine getirilen ve yapılmış olan tetkiklerinde herhangi bir nörolojik hastalık bulunmayan hastalar arasından çalışmaya katılmayı onaylayan benzer yaş gönüllüler ile oluşturuldu. Kognitif değerlendirilmeleri için mini mental test değerlendirmesi yapılıp normal sınırlarda kabul edilenler sağlıklı gönüllü kontrol grubuna alındı. MetS tanısı "National Cholesterol Education Program Adult Treatment Panel III (NCEP-ATP III)" tanı kriterlerine göre belirlendi (11)

NCEP-ATP III Metabolik Sendrom tanı Kriterleri:

1- Abdominal Obezite

(bel çevresi: kadın cinsiyet için $>88 \mathrm{~cm}$, erkek cinsiyet için $>102 \mathrm{~cm}$ ), 
2--Kan şekeri yüksekliği

(açlık kan glukozu $\geq 110 \mathrm{mg} / \mathrm{dl}$ ),

3-Serum trigliserid yüksekliği

(açlık serum trigliserid $\geq 150 \mathrm{mg} / \mathrm{dl}$ ),

4-Yüksek dansiteli lipoprotein Kolesterol ((HDL-C) düzeyinde düşüklük

( kadın cinsiyet için $<50 \mathrm{mg} / \mathrm{dl}$, erkek cinsiyet için $<40 \mathrm{mg} / \mathrm{dl}$ ),

5-Kan basıncı yüksekliği veya antihipertansif tedavi kullanımı

(sistolik $\geq 130 \mathrm{mmHg}$ ve/veya diastolik $\geq 85 \mathrm{mmHg}$ ).

**NCEP-ATP III kriterlerine göre bu beş maddeden üç yada daha fazlasının varlığı metabolik sendrom tanısı almaktadır (11).

Bel çevresi ölçümü:

Hasta ayakta dururken să̆ iliyak yarımayın en yüksek noktasından yere paralel karşı iliyak yarımaya doğru uzanan horizontal hatla, sağ aksillar orta hattan inen dikey planın kesiştiği nokta işaretlendi. Kesişme noktası referans alınarak çıplak cilt üzerinden, hafif inspiryumda, mezura yardımıyla hastanın beli kuşak gibi sarılarak ölçüldü $(11,12)$.

İstatistiksel Değerlendirmeler:

$\mathrm{Bu}$ çalışmada istatistiksel analizler NCSS 2007 paket programı ile yapıldı. Verilerin değerlendirilmesinde tanımlayıcı istatistiksel metotların (ortalama, standart sapma) yanı sıra ikili grupların karşılaştırmasında bağımsız t testi, nitel verilerin karşılaştırmalarında ki-kare testi kullanıldı. Sonuçlar, anlamlılık p<0,05 düzeyinde değerlendirildi.

\section{Bulgular}

Çalışmada olası-muhtemel 365 Alzhemer hastası ve 158 sağlıklı gönüllülerden oluşan iki grup oluşturuldu.

Alzheimer hastalarının \% 56.43'ü (n=206) kadın ve \%43.57's1 (n=159) erkek cinsiyetine sahipti. Hastaların yaş ortalaması: $71.48 \pm 8.37$, ortalama eğitim süresi: $4.42 \pm 3.64$, tanı almadan önce unutkanlık şikayetlerinin olduğu sürenin yıl olarak ortalaması: $3.89 \pm 3.06$ yıl idi. Hastaların mini mental test puan ortalama değeri: $19.60 \pm 5.75$ olarak hesapland1.

Sağlıklı kontrol grubunun \% 61.39'u (n=97) kadın ve \%38,61 (n=61) erkek cinsiyetine sahip idi. Hastaların yaş ortalaması: $66.74 \pm 8.65$, ortalama eğitim süresi: $5.81 \pm 3.88$ yıl idi. Mini mental test puan ortalama değeri: $29.20 \pm 1.27$ olarak hesapland.

Alzheimer Hastaları grubu ile sağlıklı kontrol grubu; hipertansiyon, hiperlipidemi, diyabet, HDL-C düşüklüğü, iskemik kalp hastalığı öyküsü, beyin damar hastalığı öyküsü ve metabolik sendrom varlığı açısından benzer özellikteydiler. Ancak sağlıklı kontrol grubunda; açlık kan şekeri yüksekliği ve abdominal obezite varlığı Alzheimer hastaları grubundan anlamlı olarak daha yüksek oranlara sahip idi (Tablo 1).

Tablo 1: Alzheimer hastaları ve sağlıklı gönüllü grubunda metabolik sendrom (MetS)

\begin{tabular}{|c|c|c|c|}
\hline & $\begin{array}{l}\text { Alzheimer Hastaları Grubu } \\
\qquad \mathrm{N}=365\end{array}$ & $\begin{array}{l}\text { Sağl1klı Gönüllü Grubu } \\
\text { N=158 }\end{array}$ & $\mathrm{p}$ \\
\hline Hipertansiyon (+) & $\begin{array}{c}191 \\
(\% 52,32)\end{array}$ & $\begin{array}{c}95 \\
(\% 60,12)\end{array}$ & $\mathrm{p}=0,053$ \\
\hline Serum TG yüksekliği (+) & $\begin{array}{c}179 \\
(\% 49,04)\end{array}$ & $\begin{array}{c}82 \\
(\% 51,89)\end{array}$ & $\mathrm{P}=0,724$ \\
\hline Diyabet $(+)$ & $\begin{array}{c}71 \\
(\% 19,45)\end{array}$ & $\begin{array}{c}41 \\
(\% 25,94) \\
\end{array}$ & $\mathrm{p}=0,174$ \\
\hline HDL-K düşüklüğü (+) & $\begin{array}{c}138 \\
(\% 37,80)\end{array}$ & $\begin{array}{c}65 \\
(\% 41,13)\end{array}$ & $\mathrm{p}=0,512$ \\
\hline Açlık kan şekeri yüksekliği (+) & $\begin{array}{c}117 \\
(\% 32,05)\end{array}$ & $\begin{array}{c}70 \\
(\% 44,30)\end{array}$ & $p=0,028$ \\
\hline Abdominal obezite (+) & $\begin{array}{c}74 \\
(\% 20,27)\end{array}$ & $\begin{array}{c}51 \\
(\% 32,27)\end{array}$ & $p=0,0001$ \\
\hline Metabolik sendrom (+) & $\begin{array}{c}142 \\
(\% 38,90)\end{array}$ & $\begin{array}{c}74 \\
(\% 46,83)\end{array}$ & $\mathrm{p}=0,128$ \\
\hline İskemik kalp hastalığı öyküsü (+) & $\begin{array}{c}115 \\
(\% 31,50)\end{array}$ & $\begin{array}{c}53 \\
(\% 33,54)\end{array}$ & $\mathrm{p}=0,651$ \\
\hline Beyin damar hastalığı öyküsü (+) & $\begin{array}{c}57 \\
(\% 15,61)\end{array}$ & $\begin{array}{c}22 \\
(\% 13,92)\end{array}$ & $\mathrm{p}=0,141$ \\
\hline
\end{tabular}

Kısaltmalar: TG: Trigliserid, HDL-C: Yüksek dansiteli lipoprotein kolesterol, 


\section{Tartışma}

İnsan ömrünün uzaması, ilerleyen yaş ile sıklığı artış gösteren demans konusunu yaşlı nüfusun önemli sorunları arasına yerleştirmiştir. Bu sorunun çözümünde yola çıkış noktası, demansa neden olabilen risk faktörleri tesbit edilebilir ve değiştirilip kontrol altına alınabilir ise demans önlenebilir mi? sorusu olmuştur.

Dünya Demans Konseyi (Word Demantia Consey) 2014 yılı toplantısında bazı değiştirilebilir risk faktörlerinin demans riskinin azalmasıla ilişkili olabileceğini gösteren yeterli kanıt olduğunu bildirmiştir. Düzenli fiziksel aktivitenin ve kardiyovasküler risk faktörlerinin (diyabet, obezite, sigara içme ve hipertansiyon) iyi yönetiminin bilişsel kayıp riskini azalttığını ve demans riskini azaltabileceğini ifade etmiştir. Ayrıca sağlıklı bir diyetin ve yaşam boyu öğrenme-bilişsel eğitimin de bilişsel gerileme riskini azaltabileceğini duyurmuştur (13).

Kardiyovasküler risk faktörlerinin vasküler kognitif yetmezlik etyolojisindeki yeri şüphesizdir (14). Oysa AH etyopatogenezinde kardiyovasküler risk faktörlerinin etkisi netlik kazanamamıştır. Üstelik hayat tarzı değiştirilerek önlenebilen MetS gibi çoklu kardiyovasküler risk faktörleri demetinin AH ile birlikteliği ve etyopatogenezi açıklaması konusunda yeterli veri yoktur. Var olan bilgiler de birbirinden farklı ve AH etyopatogenezi aydınlatmaya yetmemektedir $(15,16,17,18)$. Biz vaka-kontrollü olarak düzenlenen çalışmamızda AH grubumuzda MetS varlığı (\%38.90) ile sağlıklı kontrol grubumuzdaki MetS varlığını (\%46.83) benzer buldduk. AH ile MetS arasında ilişki olduğunu iddia eden populasyon temelli bir çalışmada MetS oranı \%43.6 olduğu ve MetS bulunan yaşlılarda AH oranının yüksek olduğu bilgisine ulaştık (15). Bu çalışmayı irdelediğimizde AH sayısının ( $\mathrm{n}=45)$ bizim AH grubumuzdaki hasta saysından $(n=365)$ daha az olduğunu, metabolik sendrom varlığının AH gelişiminde risk olacağı yönünde bir sonuç vermeye yetmeyeceğini düşünüyoruz. Metodolojik olarak çalışmamıza benzer şekilde vakakontrol olarak yapılan bir başka çalışmada $50 \mathrm{AH}$ ile 75 sağlam kognitif fonksiyonu olan bireylerden oluşan iki grup için MetS varlığı araştırılmış ve AH ile MetS varlığının ilişkili olabileceği şeklinde yorumlanmıştır (16). Yine bu çalışmada da hasta sayısının net bir karar vermek için yeterli olmadığını düşünüyoruz.

MetS varlığının AH gelişiminde risk olduğunu iddia eden çalışmalarda; MetS varlığının insüline dirençli beyin durumu aracılığıyla oksidatif stres ve inflamasyonu tetiklediği ve böylece AH'nın bilinen nörodejenerasyonuna katkıda bulunduğunu savunan hipotezler sunulmuştur $(17,18)$. Ancak bu hipotezler, net veriler ile ispatlanamamıştır.

MetS ve demans arasındaki ilişkiyi araștıran uzun vadeli bir çalışma ise farklı olarak; metabolik kardiyovasküler risk faktörlerinin kümelenmesinin vasküler kaynaklı demans riskini arttıracağını, AH ile ilişkisi olmadığını bildirmiştir (19). Zaten vasküler riskler açısından zengin olan vasküler kognitif yetmezlik açısından bu sonuç şaşırtıcı değildir. Ancak AH ile ilgili elde edilen sonuç bizim sunucumuz ile uyumludur. Biz kardiyovasküler riskler açısından vasküler demans hastalarını incelemedik. Ama AH grubumuzun MetS varlığı benzer yaş özellikte sağlıklı kontrol grubumuz ile benzer idi. Dahası Ülkemizde yapılmış olan otuz yaş üzeri bireylerde MetS oranı ile yakın (\%37) (20), ve yine ülkemiz akut iskemik serebrovasküler hastalık geçiren hastalarda MetS varlığından [ ( $\%$ 67.2) (21) (65 yaş üzerı hastalar için \%58,9 (22)] düşüktü. Bulgular AH tanı aldığı dönemde MetS varlığının eş yaş sağlıklı insanlar ile benzer, beyin damar hastalıklarındaki orandan ise düşük olduğunu gösterdi.

$\mathrm{Bu}$ verilerin ışığında: böyle ve benzeri çalışmaların sonuçları ile, nöropatolojik değişikliklerin hastalığın klinik bulguları ortaya çıkmadan yıllar önce başladığı bilinen bir hastalık için risk faktörleri kakkında iddialarda bulunulmasının yanıltıcı sonuçlara götürebileceğini düşünüyoruz. Ancak Helzner ve arkadaşlarının çalışmasında iddia ettiği gibi vasküler risk faktörlerinin AH na eklendiğinde yada AH'nda vasküler risk faktörlerinin varlığında hastalığın seyrine olan etkilerinin (5) daha önemli olabileceği fikrine kat1liyoruz.

Tabiiki kardiovasküler risk faktörlerinin düzenlenmesi ve tedavisi kardiyovasküler hastalıklarda çok çok önemlidir. Ancak AH'na sebep olabilecek nedenler arasında ve etyopatogenezi aydınlatabilecek yeterlilikte görünmemektedir. Bu nedenle vasküler risk faktörlerinin varlığının, eklenmesinin yada kontrol altına alınmasının, hastalığın klinik seyri üzerine etkilerini değerlendirmeye yönelik çalışmalar daha çok desteklenmelidir. Gelecekteki çalışmalarda metabolik sendrom ve/veya kardiovasküler risk faktörlerinin AH'nın ilerlemesi, ilerleme hızı, klinik tablonun ağırlaşması ve günlük yaşam aktiviteleri gibi sosyoekonomik yükü etkileyebilecek durumlar üzerine etkilerinin araştırılması daha verimli sonuçlar verebilir. AH etyopatogenezi araştırmalarında, hastalık tanısı alınan dönemde vasküler risk faktörleriyle ilgili nedensellik yönünde çalışmalara odaklanmak yerine, klinik şiddeti ve seyri değiştirebilme ihtimaline yönelmek daha pratik bir yol olarak düşünülmelidir. 


\section{Referanslar}

1. Ballard C, Gauthier S, Corbett A, Brayne C, Aarsland D, Jones E. Alzheimer's disease. Lancet. 2011 Mar 19;377(9770):1019-31.

2. Petersen RC. Mild Cognitive Impairment. Continuum (Minneap Minn) 2016;22(2):404-418

3. Chakrabarti S, Khemka VK, Banerjee A, Chatterjee G, Ganguly A, Biswas A. Metabolic Risk Factors of Sporadic Alzheimer's Disease: Implications in the Pathology, Pathogenesis and Treatment. Aging Dis. 2015;6(4):282-299.

4. Braak E, Griffing K, Arai K, Bohl J, Bratzke H, Braak H. Neuropathology of Alzheimer's disease: what is new since A. Alzheimer? Eur Arch Psychiatry Clin Neurosci. 1999;249 Suppl 3:14-22.

5. Helzner EP, Luchsinger JA, Scarmeas N, Cosentino S, Brickman AM, Glymour MM, Stern Y. Contribution of vascular risk factors to the progression in Alzheimer disease. Arch Neurol. 2009 Mar;66(3):343-8. doi: 10.1001/archneur.66.3.343.

6. Sparks DL, Hunsaker JC 3rd, Scheff SW, Kryscio RJ, Henson JL, Markesbery WR. Cortical senile plaques in coronary artery disease, aging and Alzheimer's disease. Neurobiol Aging. 1990;11(6):601-7.

7. Kivipelto M, Helkala EL, Laakso MP, Hänninen T, Hallikainen M, Alhainen K, Soininen H, Tuomilehto J, Nissinen A. Midlife vascular risk factors and Alzheimer's disease in later life: longitudinal, population-based study. BMJ. 2001;322(7300):1447-51.

8. Solomon A, Kareholt I, Ngandu T, Winblad B, Nissinen A, Tuomilehto J, Soininen H, Kivipelto M. Serum cholesterol change after midlife and late-life cognition; twenty-one-year follow up. Neurolgy 2007; 68(10): 751-6.

9. Reitz C, Tang MX, Schupf N, Manly JJ, Mayeux R, Luchsinger JA. Association of higher levels of high-density lipoprotein cholesterol in elderly individuals and lower risk of late-onset Alzheimer disease. Arch Neurol. 2010;67(12):1491-7. doi: 10.1001/archneurol.2010.297.

10. Samson SL, Garber AJ. Metabolic syndrome. Endocrinol Metab Clin North Am. 2014 Mar;43(1):1-23. doi: 10.1016/j.ecl.2013.09.009.

11. Third Report of the National Cholesterol Education Program (NCEP) Expert Panel on Detection, Evaluation, and Treatment of High Blood Cholesterol in Adults (Adult Treatment Panel III) final report. Circulation 2002; 106(25): 3143-421.

12. The practical guide identification, evaluation, and treatment of overweight and obesity in adults. Bethesda MD: National Institues of Health, 2000; NIH publication no:00-4084.

13. Baumgart M, Snyder HM, Carrillo MC, Fazio S, Kim H, Johns H. Summary of the evidence on modifiable risk factors for cognitive decline and dementia: A population-based perspective. Alzheimers Dement. 2015 Jun;11(6):718-26. doi: 10.1016/j.jalz.2015.05.016.

14. Smith EE. Clinical presentations and epidemiology of vascular dementia. Clin Sci (Lond). 2017 Jun 1;131(11):1059-1068. doi: 10.1042/CS20160607.

15. Vanhanen M, Koivisto K, Moilanen L, Helkala EL, Hänninen T, Soininen H, Kervinen K, Kesäniemi YA, Laakso M, Kuusisto J. Association of metabolic syndrome with Alzheimer disease: a population-based study. Neurology. 2006 Sep 12;67(5):843-7.

16. Razay G, Vreugdenhil A, Wilcock G. The metabolic syndrome and Alzheimer disease. Arch Neurol. 2007 Jan;64(1):93-6. 
17. Rojas-Gutierrez E, Muñoz-Arenas G, Treviño S, Espinosa B, Chavez R, Rojas K, Flores G, Díaz A, Guevara J. Alzheimer's disease and metabolic syndrome: A link from oxidative stress and inflammation to neurodegeneration. Synapse. 2017 Oct;71(10): e21990. doi: 10.1002/syn.21990.

18. Milionis HJ, Florentin M, Giannopoulos S. Metabolic syndrome and Alzheimer's disease: a link to a vascular hypothesis? CNS Spectr. 2008 Jul;13(7):606-13.

19. Kalmijn S, Foley D, White L, Burchfiel CM, Curb JD, Petrovitch H, Ross GW, Havlik RJ, Launer LJ. Metabolic cardiovascular syndrome and risk of dementia in Japanese American elderly men. The Honolulu-Asia aging study. Arterioscler Thromb Vasc Biol. 2000 Oct;20(10):2255-60.

20. Onat A, Sansoy V. Halkımızda koroner hastalığın baş suçlusu metabolik sendrom: sıklı̆̆ı, unsurları, koroner risk ile ilişkisi ve yüksek risk kriterleri. Türk Kardiyol Dern Arş 2002; 30:815.

21. Varlıbaş F, Gencer M, Örken C, Çakal N, Tireli H. Serebrovasküler Hastalıklarda Metabolik Sendrom. J.Neurol.Sci.[Turk]. 2006; 23:(2) \# 7;93-101.

22. Bozkurt M, Tekeşin A, Yağız O,Dereci H. Serebrovasküler Hastalıklarda Metabolik Sendrom. Istanbul Tip Dergisi. 2009; 1:71-75 